\title{
Author Correction: Photoinduced self-initiated graft polymerization of methacrylate monomers on poly(ether ether ketone) substrates and surface parameters for controlling cell adhesion
}

\author{
Kazuhiko Ishihara $\cdot$ Satoshi Yanokuchi $\cdot$ Kyoko Fukazawa $\cdot$ Yuuki Inoue
}

Published online: 6 April 2020

(C) The Society of Polymer Science, Japan 2020

Correction to: Polymer Journal

https://doi.org/10.1038/s41428-020-0318-9

In the original published version of Table 1, surface free energy parameters and values of some polymer substrates are incorrect. The corrected Table is as shown in below. The original article has been corrected.
Table 1 Physicochemical parameters at various polymer grafted PEEK substrate

\begin{tabular}{lcccc}
\hline Substrates & $\zeta$-potential $(\mathrm{mV})$ & \multicolumn{3}{l}{$\begin{array}{l}\text { Surface free energy } \\
\left(\mathrm{mJ} / \mathrm{m}^{2}\right)\end{array}$} \\
\cline { 3 - 5 } & & $\gamma_{\mathrm{s}}^{\mathrm{p}}$ & $\gamma_{\mathrm{s}}^{\mathrm{d}}$ & $\gamma_{\mathrm{s}}$ \\
\hline PEEK & -25.0 & 1.5 & 37.7 & 39.2 \\
PM-g-PEEK & -0.5 & 18.3 & 52.7 & 71.0 \\
PS-g-PEEK & -68.5 & 41.0 & 19.5 & 60.5 \\
PC-g-PEEK & -1.3 & 45.7 & 15.3 & 61.0 \\
PT-g-PEEK & 46.0 & 39.8 & 16.6 & 56.4 \\
PH-g-PEEK & -18.1 & 15.5 & 32.5 & 48.0 \\
PB-g-PEEK & -49.0 & 1.5 & 37.9 & 39.4 \\
\hline
\end{tabular}

